\title{
Trichloroethene and cis-1,2-Dichloroethene Concentration-Dependent Toxicity Model Simulates Anaerobic Dechlorination at High Concentrations. II: Continuous Flow and Attached Growth Reactors
}

\author{
Andrew R. Sabalowsky, ${ }^{1}$ Lewis Semprini ${ }^{2}$ \\ ${ }^{1}$ Center for Biofilm Engineering, 366 EPS Building, PO Box 173980, \\ Montana State University, Bozeman, Montana 59717-3980; telephone: 406-994-2674; \\ fax: 406-994-6098; e-mail: andy.sabalowsky@biofilm.montana.edu \\ ${ }^{2}$ School of Chemical, Biological and Environmental Engineering, Oregon State University, \\ Corvallis, Oregon
}

Received 2 March 2010; revision received 20 May 2010; accepted 24 May 2010

Published online 1 June 2010 in Wiley Online Library (wileyonlinelibrary.com). DOI 10.1002/bit.22822

\begin{abstract}
A model that was used to describe toxicity from high concentrations of chlorinated aliphatic hydrocarbons (CAHs) on reductively dechlorinating cultures in batch reactors (Sabalowsky and Semprini (in press)) was extended here to simulate observations in continuous flow suspended and attached growth reactors. The reductively dechlorinating anaerobic Evanite subculture (EV-cDCE) was fed trichloroethene (TCE) and excess electron donor to accumulate cis-1,2-dichloroethene (cDCE) in a continuous flow stirred tank reactor (CFSTR); and an attached growth recirculating packed column (RPC). A concentrationdependent toxicity model used to simulate the results of batch reactors in part I (Sabalowsky and Semprini (in press) Biotechnol Bioeng) also simulated well the observations for the CFSTR and RPC growth modes. The toxicity model incorporates $\mathrm{CDCE}$ and TCE toxicity coefficients that directly increase the cell decay coefficient in proportion with CDCE and TCE concentrations. Simulated estimates of the CDCE and TCE toxicity coefficients indicate reductively dechlorinating cells are most sensitive to high concentrations of CDCE and TCE in batch-fed growth, followed by CFSTR, with attached growth being least sensitive. The greater toxicity of TCE than $\mathrm{CDCE}$, and ratio of the modeled toxicity coefficients, agrees with previously proposed models relating toxicity to partitioning in the cell wall $\left(K_{\mathrm{M} / \mathrm{B}}\right)$, proportional to octanol-water partitioning $\left(K_{\mathrm{OW}}\right)$ coefficients.
\end{abstract}

Biotechnol. Bioeng. 2010;107: 540-549.

(C) 2010 Wiley Periodicals, Inc.

Correspondence to: Andrew R. Sabalowsky

Contract grant sponsor: U.S. EPA Western Region Hazardous Substance Center Contract grant number: R-828772

Contract grant sponsor: National Institute of Environmental Health Sciences

Contract grant number: 1P42 ES10338

Additional Supporting Information may be found in the online version of this article.
KEYWORDS: Dehalococcoides ethenogenes; reductive dechlorination; toxicity modeling; inhibition; TCE; chemostat

\section{Introduction}

In part I, batch-growth experiments with aqueous cDCE concentrations in the range of $1,000-10,000 \mu \mathrm{M}$ inhibited reductive dechlorination in mixed cultures both from biogenic $\mathrm{CDCE}$ accumulation, and short-term commercial cDCE exposure. Traditional inhibition models, including competitive inhibition and Haldane inhibition, could not simulate long-term exposure data, while the proposed toxicity model could. In this companion paper, we further apply the proposed toxicity model from part I (Sabalowsky and Semprini, in press) to two different growth modes: continuously fed suspended; and continuously fed attached growth.

Inhibition and toxicity from high concentrations of CAHs has been documented in reductive dehalogenation studies (Adamson et al., 2004; Chu, 2004; Duhamel et al., 2002; Yang and McCarty, 2000; Yu and Semprini, 2004). The vast majority of studies in chlorinated aliphatic hydrocarbon (CAH) dechlorination use batch-fed suspended growth systems, due to their simplicity of operation. However, both planktonic and attached cells can both occur in the environment. It is therefore important to understand how batch growth data can be related to results more representative of in situ conditions and above ground reactor systems, such as continuously fed suspended- and attached-growth systems. It has commonly been observed that chemostat grown cells exhibit increased resistance to 
inhibition or toxicity compared to batch grown cells (Chang and Alvarez-Cohen, 1996; Piringer and Bhattacharya, 1999; Qu and Bhattacharya, 1997), and attached growth cells have greater resistance than suspended cells (Harrison et al., 2007; Stewart and Costerton, 2001; Walters et al., 2003). Comparisons between different growth modes (such as batch-grown, continuously fed, or attached growth) are therefore valuable regarding issues of inhibition or toxicity. Such comparisons can supply important information needed for designing treatment strategies or relating batch-fed microcosms to field observations or predictions. Feasibility demonstrations of biologically enhance tetrachloroethene (PCE) dissolution have been performed in batch- and attached-growth systems, but explaining lost activity from $\mathrm{CAH}$ accumulation has yet to be achieved (Adamson et al., 2004; Amos et al., 2007; Cope and Hughes, 2001; Sleep et al., 2006; Yang and McCarty, 2000, 2002).

Only a few studies have been devoted to evaluating biological reductive dechlorination in continuous flow suspended growth systems (Carr et al., 2000; Drzyzga et al., 2001; Yang and McCarty, 1998; Zheng et al., 2001), but we are only aware of one such study that specifically operated at relatively high CAH concentrations (Carr et al., 2000), which resulted in lost dechlorination capabilities as $\mathrm{cDCE}$ accumulated above $600 \mu \mathrm{M}$. While attached growth studies regarding biological reductive dechlorination are more numerous (e.g., Azizian et al., 2008; Isalou et al., 1998; Kao et al., 2001; Ma et al., 2006; Singhal et al., 2007; Sleep et al., 2006), few studies compare batch suspended growth to attached growth using the same starting culture (Azizian et al., 2008; Schaefer et al., 2009). Several studies have utilized attached growth in pack columns to achieve enhanced dissolution of PCE, resulting in high CDCE concentrations, but comparisons to other growth modes have yet to be made (Cope and Hughes, 2001; Sleep et al., 2006; Yang and McCarty, 2000, 2002).

Reported here are the effects of high CAH concentrations (cDCE $\sim 10,000 \mu \mathrm{M}$ and TCE $>1000 \mu \mathrm{M}$ ) on different growth modes, and simulations of the experimental observations. The $\mathrm{CAH}$ concentration-dependent toxicity model developed in part I (Sabalowsky and Semprini, in press) for batch-fed growth was applied to two other growth modes: continuously fed suspended growth, and continuously fed attached growth. cDCE accumulation effects on dechlorination activity were studied in a continuous flow stirred tank reactor (CFSTR), and an attached growth recirculating packed column (RPC). The toxicity model presented in part I simulated the transient responses of $\mathrm{CDCE}$ and TCE concentrations in both of these systems and the ultimate reactor failure that occurred.

\section{Materials and Methods}

\section{Chemicals and Analytical Methods}

The chemicals for media and analytic standards utilized in this study are presented elsewhere (Sabalowsky and
Semprini, in press). Gas chromatography for all CAHs and ethene (ETH) were also as previously described (Sabalowsky and Semprini, in press). Additionally, organic acids analyses were analyzed by high pressure liquid chromatography (HPLC) on a Dionex-500 HPLC with a Prevail Organic Acid $5 \mathrm{u}$ column $(250 \mathrm{~mm} \times 4.6 \mathrm{~mm}$ ID, Alltech, Deerfield, IL) with a $25.0 \mathrm{mM} \mathrm{KH}_{2} \mathrm{PO}_{4}$ and $17.3 \mathrm{mM} \mathrm{H}_{3} \mathrm{PO}_{4}$ elluent. An ultraviolet lamp (UV) detector was used at $210 \mathrm{~nm}$ for signal quantification. Protein measurements were made with the Pierce Micro $\mathrm{BCA}^{\mathrm{TM}}$ Protein Assay Preparation Reagent Set (Pierce, Rockford, IL) per manufacturer's instructions. Measurements were made with a HP 8453 UV/VIS spectrophotometer on the visible lamp, quantified at $562 \mathrm{~nm}$, with a detection limit of $0.5 \mathrm{mg} / \mathrm{L}$.

\section{Culture}

The EV-cDCE subculture described in part I was used for the CFSTR and RPC studies presented here. The culture was maintained under batch growth conditions as previously described prior to adding to the CFSTR and the RPC (Sabalowsky and Semprini, in press).

\section{CFSTR Construction and Operation}

A zero-headspace CFSTR was constructed with a $303 \mathrm{~mL}$ Kimax bottle fitted with a three-hole stainless steel cap and completely mixed with a Teflon stirbar. The CFSTR reactor was connected to an Orion M361 syringe pump (Thermo Electron Corp., Beverly, MA) with PEEK tubing and valves (Upchurch Scientific, Oak Harbor, WA) for influent and effluent sampling (Fig. 1). Pumping rates were periodically changed in response to reactor performance. Pumping rates and corresponding hydraulic residence times are summarized in Table I. The majority of operation was at an influent flow rate of $18 \mathrm{~mL} /$ day, resulting in a hydraulic retention time of 16.8 days.

The CFSTR was inoculated from inside an anaerobic glove box with $5 \% \mathrm{H}_{2}, 95 \% \mathrm{~N}_{2}$ atmosphere (Coy Laboratory Products, Inc., Grass Lake, MI) with $303 \mathrm{~mL}$ of the EV-cDCE culture. The reactor was then capped, exported from the glove box, and connected to influent and effluent waste collection lines as illustrated in Figure 1. More details of reactor construction are supplied by Sabalowsky (2008).

The influent was continuously supplied to the CFSTR using a $100 \mathrm{~mL}$ gastight syringe (Hamilton, Leno, NV). Batches of influent solution were made by augmenting basal growth medium (Yu and Semprini, 2004) in a $250 \mathrm{~mL}$ media bottle with excess neat TCE to achieve an average aqueous concentration of $7.4 \mathrm{mM}( \pm 0.95 \mathrm{mM} \mathrm{SD})$ and sodium lactate to $25.6 \mathrm{mM}( \pm 4.0 \mathrm{mM} \mathrm{SD})$ as a fermenting substrate. The influent solution was stirred and settled (to remove TCE NAPL from suspension), and one syringe-volume of feedstock was extracted from the $\mathrm{N}_{2}$-pressurized media bottle. The influent syringe was refilled, and more TCElactate amended medium was prepared as necessary. To 


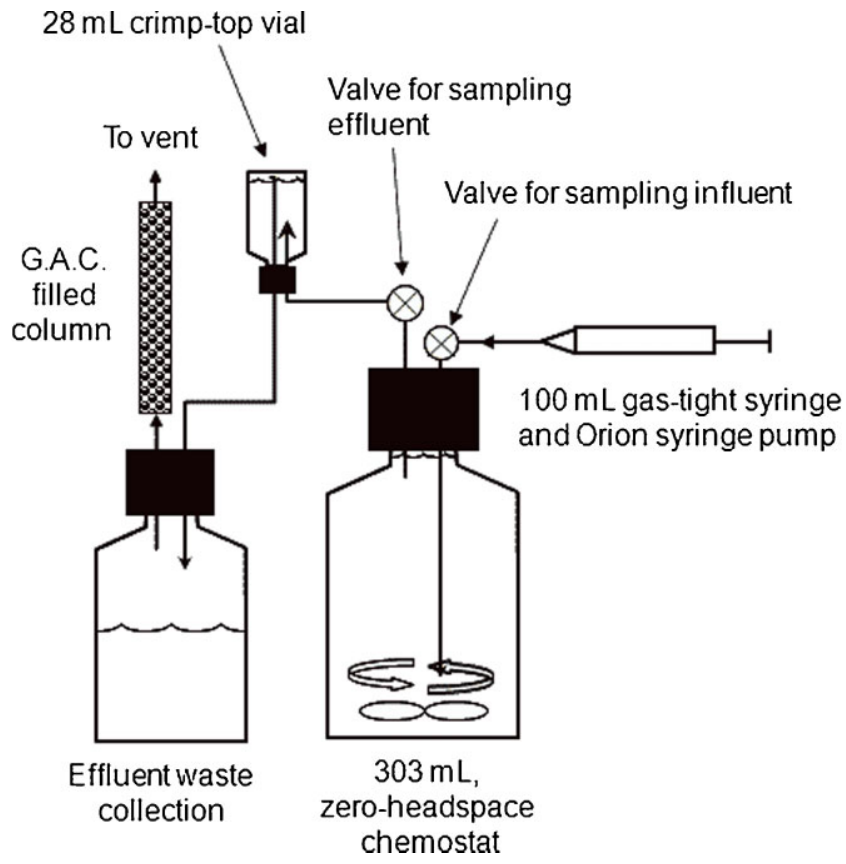

Figure 1. CFSTR schematic diagram. Not to scale.

avoid oxygen exposure, the reactor influent valve was closed and $2 \mathrm{~mL}$ of feed were flushed through the line prior to opening the influent valve to the CFSTR. Resazurin was added as an oxygen indicator. It was never oxidized during reactor operation based on the lack of a visible color change. The influent medium was carbonate buffered, and the effluent $\mathrm{pH}$ remained between 6.8 and 7.6 throughout the operation.

\section{RPC Reactor Construction and Operation}

The RPC reactor (Fig. 2) was constructed using a $30 \mathrm{~cm} \times 2.5 \mathrm{~cm}$ (ID) glass Kontes Chromaflex column with PTFE end fittings and $20 \mu \mathrm{m}$ polyethylene bed support frits

Table I. Reactor operating conditions.

\begin{tabular}{crl}
\hline Days of operation & Pumping rate (mL/day) & Residence time (days) \\
\hline CFSTR $^{\mathrm{a}}$ & 0 & - \\
$0-3$ & 28 & 10.8 \\
$4-5$ & 18 & 16.8 \\
$6-49$ & 0 & - \\
$50-55$ & 18 & 16.8 \\
56 & 12 & 25.3 \\
$57-84$ & 0 & - \\
$85-99$ & & \\
RPC $^{\mathrm{b}}$ & 6 & 11.8 \\
$0-100$ & 12 & 5.9 \\
$101-155$ & & \\
\hline
\end{tabular}

${ }^{\mathrm{a}} \mathrm{CFSTR}$ influent concentrations (average \pm standard deviation): 7.4 $( \pm 0.95) \mathrm{mM}$ TCE, $25.6( \pm 4.0) \mathrm{mM}$ lactate.

${ }^{\mathrm{b}} \mathrm{RPC}$ influent concentrations (average \pm standard deviation): 11.3 $( \pm 2.5) \mathrm{mM}$ TCE, $22.6( \pm 6.2) \mathrm{mM}$ lactate.
(Kontes, Vineland, NJ). The column was packed with $2 \mathrm{~mm}$ glass beads and connected with $1 / 8^{\prime \prime}$ PEEK tubing $\left(0.062^{\prime \prime}\right.$ ID) to a recirculating pump consisting of a Masterflex L/S 7550 computerized driver and Masterflex Micropump (Cole-Parmer Instrument Co., Vernon Hills, IL). The glass beads were etched to enhance roughness and cellular attachment with a chromic and hydrochloric acid procedure as described by Shellenberger and Logan (2002), thoroughly rinsed, autoclave sterilized and oven dried. The column was packed with the glass beads and oriented vertically for upflow operation. T-valve PEEK connections below and above the column allowed influent and effluent liquid sampling. A $25 \mathrm{~mL}$ gastight syringe (Hamilton) on an Orion M361 syringe pump was used for feed addition and connected to the influent $T$-valve connection. A $T$-connection at the top of the recirculating column system allowed effluent to leave the reactor by pressure into an anaerobically prepared waste collection bottle.

To allow culture assessment without interrupting RPC operation two mini-columns, that could be removed, were connected at the influent and effluent ends of the main packed column (Fig. 2). The inline mini-column cartridges were constructed from $1 / 4^{\prime \prime}$ (ID) glass tubing filled with the $2 \mathrm{~mm}$ glass beads, and placed below and above the column, with $T$-valve connections and 1/16" PEEK tubing bypass loops. Each packed mini-column had a liquid volume of $0.72 \mathrm{~mL}$. The entire RPC assembly liquid volume, including tubing and valves, was determined from a bromide tracer test to be $70.8 \mathrm{~mL}$.

Prior to inoculation, the RPC assembly was bleach sterilized, flushed with sterile anaerobic water, flushed and filled with basal anaerobic medium. To inoculate the RPC, $100 \mathrm{~mL}$ of the EV-cDCE subculture was extracted from the batch growth reactor with a $100 \mathrm{~mL}$ gastight syringe (Hamilton) within the anaerobic glove box, removed from the glove box, and injected up through the column at a rate of $2 \mathrm{~mL} / \mathrm{min}$ without recirculation, until $90 \mathrm{~mL}$ of culture had been flushed up through the $70.8 \mathrm{~mL}$ system. The recirculating and influent pumps were then immediately started. Influent pumping rates, TCE, and lactate concentrations are summarized in Table I. To distribute activity throughout the length of the column, the recirculating pump speed was set to $2 \mathrm{~mL} / \mathrm{min}$, resulting in a $35 \mathrm{~min}$ circulation time through the system.

Growth media for the RPC were prepared in the same fashion as the CFSTR, by augmenting the basal medium with $60 \%$ sodium lactate syrup and excess TCE. As with the CFSTR, the influent syringe was refilled as needed, flushing influent lines each time to maintain anaerobic conditions. Periodic effluent $\mathrm{pH}$ monitoring confirmed RPC $\mathrm{pH}$ remained between 6.8 and 7.4. For both the RPC and CFSTR, in order to avoid hydrogen limitations on dechlorination, lactate was supplied at approximately 5-6 times the required hydrogen supply to dechlorinate TCE to cDCE, based upon lactate fermentation to acetate and hydrogen, as has been observed in our lab for this culture. 


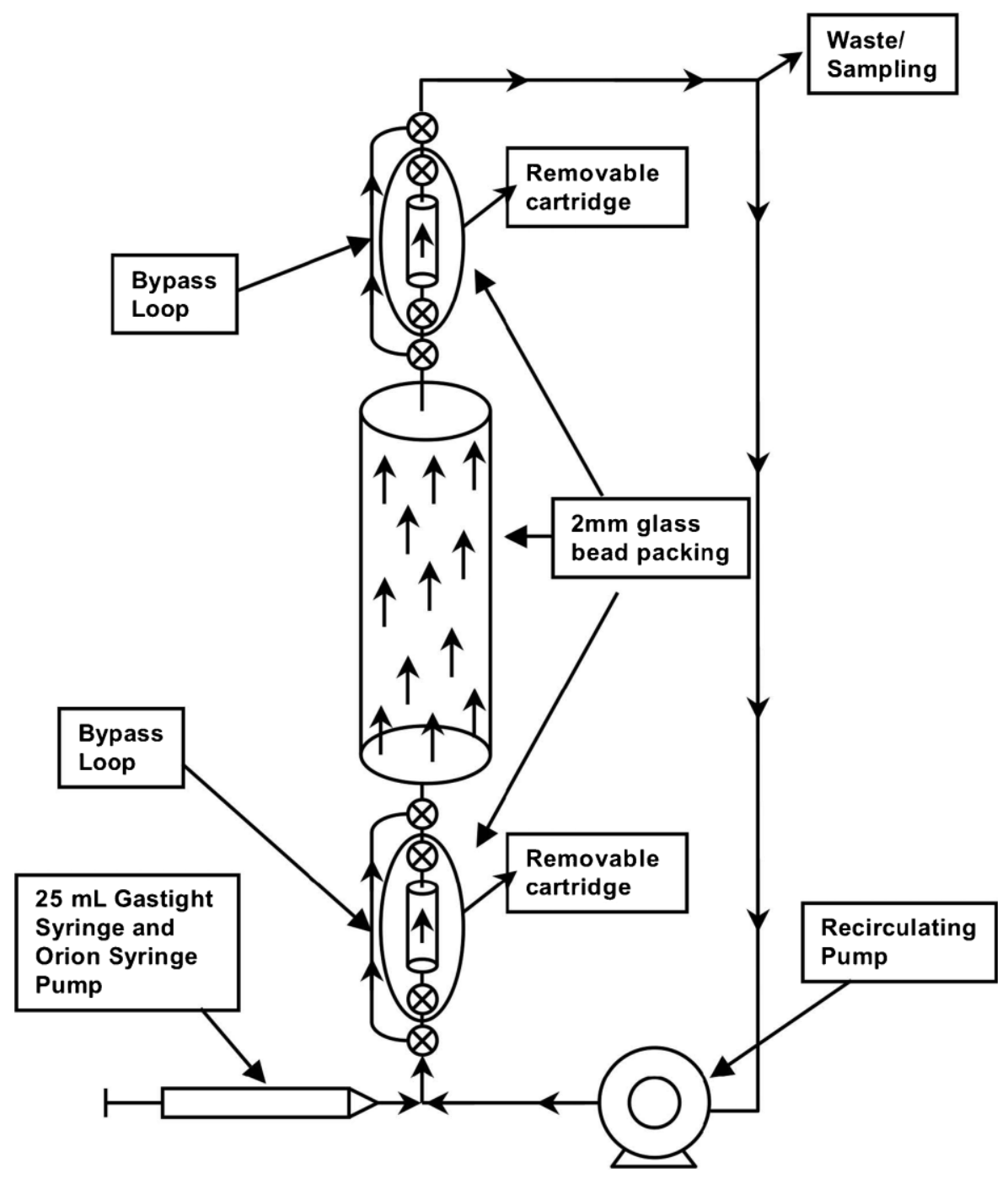

Figure 2. RPC schematic diagram. Not to scale.

\section{CFSTR and RPC Sampling}

Liquid samples from the CFSTR and RPC were collected by pumping $1.5 \mathrm{~mL}$ from the influent syringe into the system and extracting $1.5 \mathrm{~mL}$ of effluent or influent instantaneously from the appropriate sampling port with a disposable $3.0 \mathrm{~mL}$ syringe. A headspace sample for GC analysis was created by injecting $1.0 \mathrm{~mL}$ of liquid sample into a $2.0 \mathrm{~mL}$ crimp-top clear glass vial. The vials were vortexed for $1 \mathrm{~min}$ at room temperature $\left(22.5-25.5^{\circ} \mathrm{C}\right)$, and $100 \mu \mathrm{L}$ of headspace was extracted and injected into the GC-FID injection port for $\mathrm{CAH}$ and ETH quantification. Gaseous and aqueous concentrations, and total mass for CAHs, and ETH were calculated based upon sampling temperatures, Henry's Law coefficients (Gossett, 1987; Perry et al., 1997) and the relationships of $H_{\mathrm{cc}}=C_{\mathrm{g}} / C_{\mathrm{l}}, M_{\mathrm{total}}=C_{\mathrm{g}} V_{\mathrm{g}}+C_{\mathrm{l}} V_{\mathrm{l}}$.

Twice during operation, the $0.72 \mathrm{~mL}$ mini-columns were taken offline to assess attached growth activity associated with the glass beads. The mini-columns were flushed with
$5 \mathrm{~mL}$ of fresh basal medium (containing no lactate or TCE), and then TCE- and lactate-augmented medium $(1,120 \mu \mathrm{M}$ and $25,000 \mu \mathrm{M}$, respectively) was added. The columns were incubated for $18 \mathrm{~h}$ at $20^{\circ} \mathrm{C}$. The total amount of $\mathrm{cDCE}$ formed was determined by extracting the aqueous contents into a $5.0 \mathrm{~mL}$ Hamilton Gastight syringe, analyzing TCE and CDCE on a GC-FID fitted with a purge-and-trap apparatus. Details of the purge-and-trap analysis are provided elsewhere (Azizian et al., 2008). Average TCE dechlorination rates were determined by dividing CDCE moles formed by the incubation time and the volume.

\section{Model Development}

\section{Michaelis-Menten Kinetics for Reductive Dechlorination}

Relevant Michaelis-Menten based kinetics, including inhibition, are presented in part I (Sabalowsky and 
Semprini, in press). Here, we expand the previously presented equations to the CFSTR and RPC reactor studies.

\section{CFSTR Modeling}

The kinetic and toxicity models for the batch reactors as presented in part I can be incorporated into CFSTR modeling for TCE dechlorination as follows,

$$
\frac{\mathrm{d} C_{\mathrm{L}, \mathrm{TCE}}}{\mathrm{d} t}=\frac{Q}{V} C_{\mathrm{L}, \mathrm{TCEin}}-\frac{Q}{V} C_{\mathrm{L}, \mathrm{TCE}}-\frac{k_{\mathrm{max}, \mathrm{TCE}} X C_{\mathrm{L}, \mathrm{TCE}}}{K_{\mathrm{S}, \mathrm{TCE}}+C_{\mathrm{L}, \mathrm{TCE}}}
$$

where $Q$ is the volumetric flow rate, and $V$ is the reactor volume, and $C_{\mathrm{L}, \mathrm{TCE} i n}$ is the TCE concentration in the influent. All other parameters are as defined and summarized in the Nomenclature of part I. Assumptions are that the dechlorination reaction stops at $\mathrm{CDCE}$, which is a property of the EV-cDCE subculture, and the reactions are not electron donor limited. The CFSTR equation for CDCE (not shown) would include the inflow and outflow terms for CDCE and the CDCE production term, which is the positive form of the TCE transformation rate term shown above.

CFSTR dehalogenating biomass concentration can be modeled by modifying Equation (2) of part I as follows,

$$
\frac{\mathrm{d} X}{\mathrm{~d} t}=\frac{Q}{V} X_{\mathrm{in}}-\frac{Q}{V} X+Y\left(\frac{k_{\mathrm{max}, \mathrm{TCE}} X C_{L, \mathrm{TCE}}}{K_{\mathrm{S}, \mathrm{TCE}}+C_{\mathrm{L}, \mathrm{TCE}}}\right)-k_{\mathrm{d}}^{*} X
$$

where $X_{\text {in }}$ would be biomass concentration introduced in the influent, which was zero for these experiments. The $k_{\mathrm{d}}^{*}$ term represents the concentration based toxicity decay term defined in Equation (8) of part I.

\section{RPC Modeling}

The above biomass CFSTR equation was expanded to a simplified RPC model by the incorporation of a fraction of biomass suspended, to account for sloughing of cells, as follows.

$$
\frac{\mathrm{d} X}{\mathrm{~d} t}=\frac{Q}{V} X_{\mathrm{in}}-\frac{Q}{V} X f_{\mathrm{s}}+Y\left(\frac{k_{\mathrm{max}, \mathrm{TCE}} X C_{\mathrm{L}, \mathrm{TCE}}}{K_{\mathrm{S}, \mathrm{TCE}}+C_{\mathrm{L}, \mathrm{TCE}}}\right)-k_{\mathrm{d}}^{*} X
$$

where $f_{\mathrm{s}}$ represents the fraction of cells suspended, assumed to be 0.15 , meaning $15 \%$ of cells in the reactor are subject to loss by advection from the system while the remaining biomass is retained. Measured cell sloughing in a laminar tube reactor has been reported to range from $10 \%$ to $25 \%$ (Telgmann et al., 2004). A constant rate of cell sloughing, as modeled here, is an approach used by Schaefer et al. (2009). Since this system was operated with high CDCE and TCE concentrations, the biofilm is assumed to be fully penetrated, and therefore that $k_{\max , \mathrm{TCE}}$ and $K_{\mathrm{S} \text {,TCE }}$ values are the same as the suspended culture, thus allowing us to model the dechlorination kinetics for the RPC with the same kinetic equations used to describe the CFSTR. A summary of
Table II. Model kinetic parameters for batch, CFSTR, and RPC simulations. ${ }^{\mathrm{a}}$

\begin{tabular}{lccc}
\hline Parameter & Batch & CFSTR & RPC \\
\hline$k_{\max , \mathrm{TCE}}(\mu \mathrm{mol} / \mathrm{mg}$ protein/day $)$ & $28^{\mathrm{b}}$ & 28 & 28 \\
$K_{\mathrm{s}, \mathrm{TCE}}(\mu \mathrm{M})$ & $1.8^{\mathrm{b}}$ & 1.8 & 1.8 \\
$K_{\mathrm{t}, \mathrm{TCE}}(\mu \mathrm{M})$ & $230^{\mathrm{c}}$ & 400 & 770 \\
$K_{\mathrm{t}, \mathrm{CDCE}}(\mu \mathrm{M})$ & $800^{\mathrm{b}}$ & 2,020 & 2,600 \\
$X_{0}(\mathrm{mg}$ protein/L) & $0.8^{\mathrm{b}}$ & 22.5 & 20 \\
\hline
\end{tabular}

${ }^{a}$ All competitive inhibition and yield coefficients, which are not listed here, are as reported previously for EV culture (Yu and Semprini, 2004).

${ }^{\mathrm{b}}$ As supplied in Table I, part I.

${ }^{\mathrm{c}}$ As calculated for modeling in Figure 4b, part I. Calculated based upon the $K_{\mathrm{t}, \mathrm{CDCE}}$ value from part $\mathrm{I}$, and the assumed relationship: $K_{\mathrm{t}, \mathrm{TCE}} /$ $K_{\mathrm{t}, \mathrm{cDCE}}=K_{\mathrm{M} / \mathrm{B}, \mathrm{cDCE}} / K_{\mathrm{M} / \mathrm{B}, \mathrm{TCE}}$ per Equations (8) and (10), part I (Sabalowsky and Semprini, in press).

kinetic modeling parameters and values for CFSTR and RPC models utilized in this study are presented in Table II. All models were constructed and solved using the STELLA ${ }^{\circledR}$ v.9.0 software (Isee Systems, Inc., Lebanon, NH).

\section{Results and Discussion}

\section{CFSTR Observations}

The CAH monitoring data, along with model simulations, are presented in Figure 3a. Pumping rates were adjusted throughout the experiment, as presented in Figure $3 \mathrm{a}$ and Table I. From days 8 to 31 of operation, with a 16.8-day retention time, the CFSTR maintained nearly complete dechlorination of TCE to CDCE, with no detectable VC or ETH, and only traces of TCE generally below $12 \mu \mathrm{M}$. TCE began to increase after day 31 , and the reactor was operated in stop-flow mode from days 50 to 56 until TCE was reduced below $110 \mu \mathrm{M}$. Pumping was resumed for one day with the 16.8-day retention time, but increasing TCE was observed in the effluent, and the influent rate was then reduced to $12 \mathrm{~mL} /$ day, to produce a retention time of 25.3 days. TCE continued to increase in the effluent as pumping was maintained, and pumping was stopped after day 85 to determine if the reactor would recover performance, as it had during stop-flow initiated on day 50 . No observable dechlorination was measured from day 85 to 99 , and thus the experiment was terminated. Effluent organic acids monitoring revealed excess propionate was always present above $5 \mathrm{mM}$ (not shown) from the fermentation of lactate at an average influent lactate concentration of $25.6 \mathrm{mM}$.

\section{CFSTR Modeling}

The CFSTR model to simulate observed performance included transformation kinetics as described in Equation (1), plus the CDCE and TCE toxicity terms, $K_{\mathrm{t}, \mathrm{CDCE}}$ and $K_{\mathrm{t}, \mathrm{TCE}}$, as shown in Equation (8) of part I (Sabalowsky and Semprini, in press). As with other research 

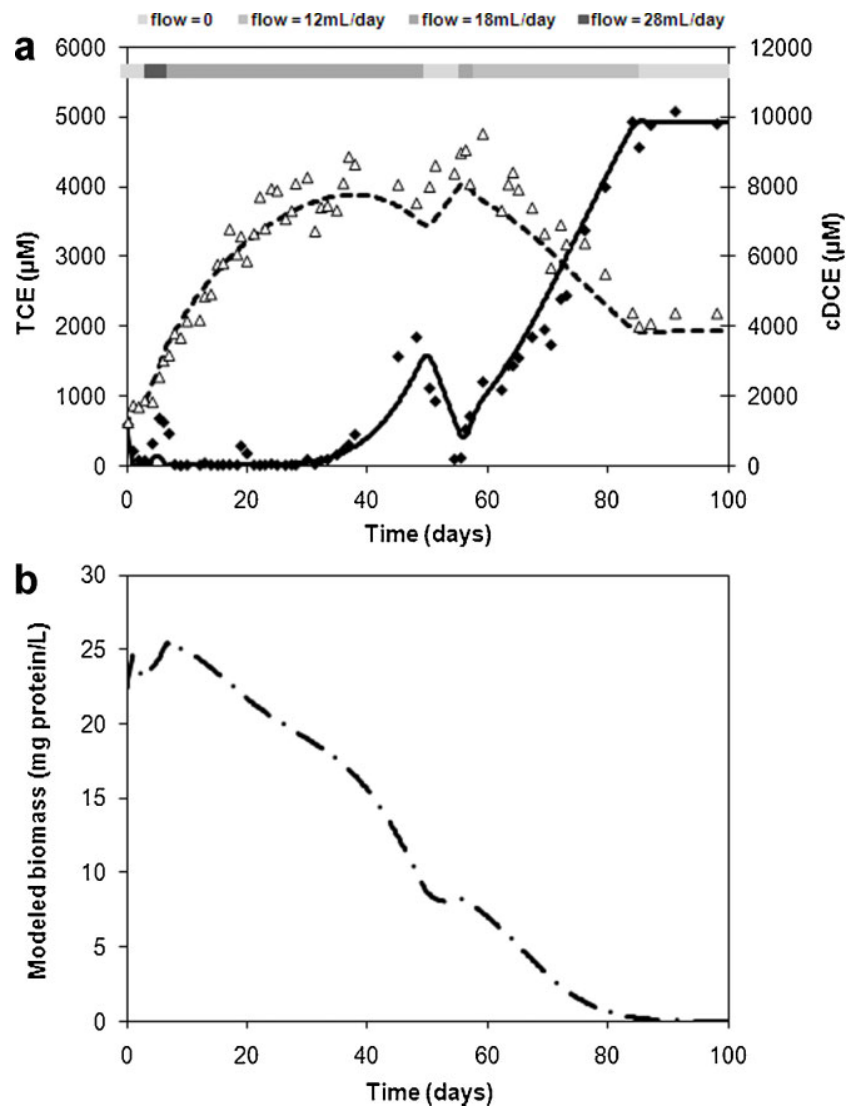

Figure 3. CAH monitoring data for the CFSTR with fitted CAH concentrationdependent toxicity model. CAH monitoring data and modeled values (a), and modelpredicted biomass $(\mathbf{b})$. TCE data ( $\bullet$ ), cDCE data $(\Delta)$, modeled TCE (solid line), modeled CDCE (dashed line), and modeled protein concentrations (dash-dot line). Note the different scales for TCE and CDCE concentrations.

investigating $\mathrm{CAH}$ dechlorination (Amos et al., 2007; Cupples et al., 2004; Sabalowsky and Semprini, in press), the CFSTR model was calibrated by adjusting the initial biomass $\left(X_{0}\right)$ to fit the observed dechlorination between days 0 and 3 at no-flow conditions (Fig. $3 \mathrm{a}$ ). The $k_{\max , \mathrm{TCE}}$ from the batch reactor simulation, as well as all other $k_{\max }$ and $K_{\mathrm{S}}$ values listed in part I, were used. Flow changes during operation were included in the model input, and a constant modeled TCE influent concentration of $8,900 \mu \mathrm{M}$ maintained a mass balance consistent with effluent $\mathrm{CAH}$ measurements.

Modeling was initially performed using only cDCE toxicity, and the same $K_{\mathrm{t}, \mathrm{cDCE}}$ as used for the batch experiments of part I. Model simulations using these parameters predicted premature CFSTR failure, losing dechlorination activity by day 30 , indicating a $K_{\mathrm{t}, \mathrm{cDCE}}$ of $800 \mu \mathrm{M}$ caused too much toxicity to match experimental observations. This result was expected, as continuously fed cells in chemostats, similar to our CFSTR, have exhibited greater tolerance to toxicity than batch-fed cells (Chang and Alvarez-Cohen, 1996; Piringer and Bhattacharya, 1999; Qu and Bhattacharya, 1997). Though the mechanisms have yet to be determined, acclimation to toxic or inhibitory conditions in continuous cultures or a shift in the microbial community is possible. Acclimation to toxicity in continuous cultures has been previously observed (Gupta et al., 1996; Piringer and Bhattacharya, 1999; Qu and Bhattacharya, 1996). The $K_{\mathrm{t}, \mathrm{cDCE}}$ toxicity coefficient was therefore adjusted to reflect the observed TCE accumulation and $\mathrm{CDCE}$ decline beginning after day 56. After setting the $K_{t, c D C E}$ coefficient, the TCE toxicity coefficient $\left(K_{t, T C E}\right)$ was adjusted to fit the TCE increase and CDCE decrease observed between days 56 and 90 .

Both the $K_{\mathrm{t}, \mathrm{CDCE}}$ and $K_{\mathrm{t}, \mathrm{TCE}}$ coefficients are sensitive and were fit to provide good match to the experimental observations. Sensitivity analyses to these coefficients are supplied in the Supplemental data section, including Figures S1a and S1b. As discussed in the Supplemental data section the simulations are very sensitive to changes in the $K_{\mathrm{t}, \mathrm{CDCE}}$ and $K_{\mathrm{t} \text {,TCE }}$ coefficients by $\pm 10 \%$ of the base case values and illustrate the non-linear nature of the model solutions.

Simulations with the adjusted coefficients better reflected the transient TCE increases observed from days 3 to 8 , and days 31 to 56 (Fig. 3a). Modeling the CFSTR data with only cDCE toxicity, or only TCE toxicity could not simulate the transient TCE peaks observed starting on days 3 and 31, and reactor failure commencing at day 56 of operation. Only when both CDCE and TCE toxicity terms were included were reasonable matches to $\mathrm{CAH}$ observations obtained (Fig. 3a). Unlike the batch experiments in part I, continuous exposure to high TCE concentrations occurred in the CFSTR, which is why the batch cDCE accumulation experiments (Fig. 2, part I) could be simulated without including TCE toxicity $\left(K_{\mathrm{t}, \mathrm{TCE}}\right)$. Simulated biomass from the toxicity model is shown in Figure 3b. As shown in Equation (1), the TCE dechlorination rate is directly proportional to the amount of biomass present. The decrease in the simulated biomass is fairly continuous throughout the test and is associated the early increase in CDCE and the latter increase in TCE concentration.

The ratio of $K_{\mathrm{t}, \mathrm{CDCE}} / K_{\mathrm{t}, \mathrm{TCE}}$ in the model simulation that exhibited a good fit to the data was 5.0, similar to the ratio of $K_{\mathrm{OW}}$ for TCE/cDCE (3.6), and the $K_{\mathrm{M} / \mathrm{B}}$ ratio for TCE/cDCE (3.5), as discussed in part I. This is consistent with previous work regarding the relationship between toxicity and the $K_{\mathrm{OW}}$ or $K_{\mathrm{M} / \mathrm{B}}$ of a solvent (Chu, 2004; Chu et al., 2006; Isken et al., 1999; Sikkema et al., 1994), as represented by Equation (10) in part I. Addition of Yu and Semprini's (2004) Haldane inhibition terms to the toxicity model could not produce a model fit to the data, nor could modeling with only the Haldane inhibition model previously reported (Yu and Semprini, 2004), which did not predict reactor failure. Adapting the threshold model (Eq. 7, part I) to include the CFSTR advection terms with cDCE threshold inhibition alone, TCE threshold inhibition alone, or both cDCE and TCE threshold inhibition also could not fit CAH observations, either predicting complete reactor failure by day 30, or continued complete dechlorination of TCE to $\mathrm{CDCE}$ 
without failure (not shown). Various inhibition models were unable to describe CAH data in our CFSTR experiment, but the previously described toxicity model (Sabalowsky and Semprini, in press) fit the data quite well with a small modification to the toxicity parameters. These observations suggest the proposed toxicity model more accurately describes long-term exposure to high $\mathrm{CAH}$ concentrations than inhibition models. Direct measurements of the individual toxicity coefficients on short-term experiments in continuous-fed mode are required to directly compare continuously fed cell responses to batch-fed cells and to test the proposed model. Measurements of batch rates with cells harvested temporally from the reactors and application of DNA based molecular methods to quantify the dehalogenating population, as described by Sabalowsky (2008), should be applied in future tests.

\section{RPC Observations}

The RPC CAH monitoring data and the simulation using the toxicity model are presented in Figure 4a. TCE dechlorination to $\mathrm{cDCE}$ was maintained from days 9 to

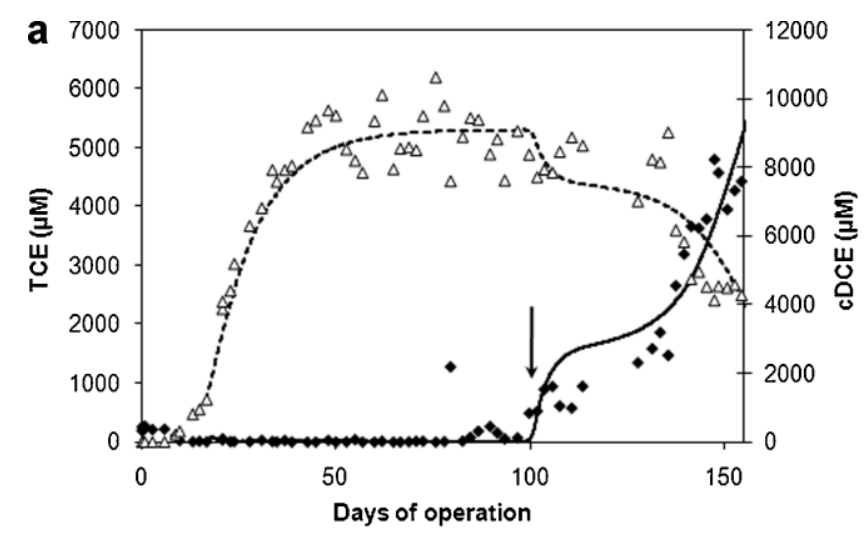

b

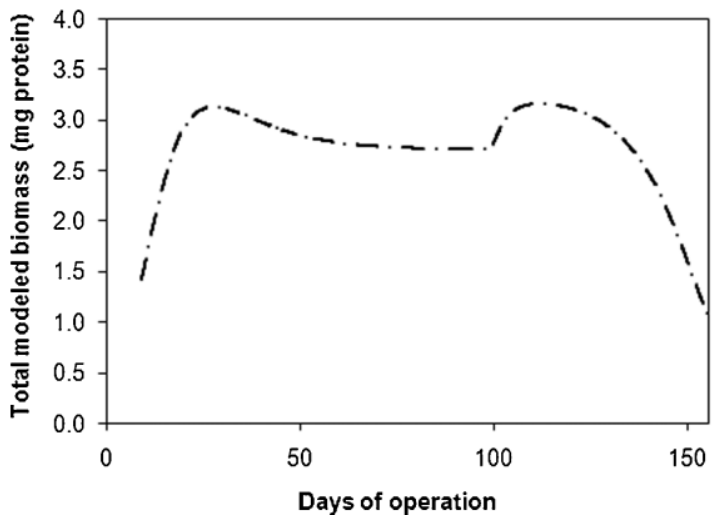

Figure 4. $\mathrm{CAH}$ monitoring data for the RPC with fitted $\mathrm{CAH}$ concentrationdependent toxicity model. CAH monitoring data and modeled values (a), and model-predicted biomass (b). TCE data ( $\diamond), \operatorname{CDCE}$ data $(\Delta)$, modeled TCE (solid line), modeled CDCE (dashed line), and modeled protein concentrations (dash-dot line). Arrow indicates when pumping increased from 6 to $12 \mathrm{~mL} /$ day (day 101). Note the different scales for TCE and CDCE concentrations.
78, with no detectable VC or ETH. Only traces of TCE below $41 \mu \mathrm{M}$ were measured in the effluent, compared to an average influent TCE concentration of $11,300 \mu \mathrm{M}$ during the $6 \mathrm{~mL} /$ day pumping ( 11.8 days hydraulic residence time). Modeled TCE effluent concentrations were between 5.8 and $75 \mu \mathrm{M}$ during this time frame. A transient increase in TCE concentration to $1,280 \mu \mathrm{M}$ observed on day 79 resulted from an overnight pumping problem, which was removed below $18 \mu \mathrm{M}$ by day 82 under resumed normal operating conditions. On day 101, the influent pump rate was increased to $12 \mathrm{~mL} /$ day to decrease the hydraulic residence time from 11.8 to 5.9 days. TCE began to increase in the effluent, remained relatively constant between 894 and $1,350 \mu \mathrm{M}$ from day 103 to 127 , but then sharply increased as cDCE concentrations decreased from days 127 to 155 , when the experiment was terminated.

Twice during operation, days 77 and 150, the two minicolumns were removed from the RPC and tested for attached growth TCE transformation activity. Average rates of TCE dechlorination over the 18-h incubations are summarized in Table III along with estimated RPC dechlorination rates and the model's simulated biomass for comparison. Rates in the mini-columns were in the range of the dechlorination rates observed in the RPC on the same days. The rates obtained for each mini-column were within $5-10 \%$ of each other, thus TCE transformation rates were essentially the same at the influent and effluent ends of the RPC. These analyses confirmed that TCE dechlorination to CDCE was associated with cells attached to the beads in the mini-columns, and that the $2 \mathrm{~mL} / \mathrm{min}$ recirculation rate successfully distributed equal activity throughout the length of the RPC. The mini-column rates were approximately 50\% higher than the average total RPC reactor dechlorination rates, but are in reasonable agreement considering the potential differences in test conditions. The mini-columns' rates clearly showed the decreased performance with time in the RPC with rates on day 150 decreasing to $49 \%$ to $52 \%$ of those on day 77, while the RPC data showed a decrease to $59 \%$. The model-simulated total biomass, also shown in Table III, showed a decline to $63 \%$ of the biomass present on day 77 by day 150. Thus there is good agreement with the measured decreases in transformation rates and the simulated decreases in biomass.

Effluent samples were periodically collected for organic acid and protein analyses. Effluent organic acids consistently

Table III. Mini-column and average RPC dechlorination rates.

\begin{tabular}{lcccc}
\hline $\begin{array}{l}\text { Day of } \\
\text { operation }\end{array}$ & $\begin{array}{c}\text { Influent } \\
\text { column rate } \\
(\mu \mathrm{mol} / \mathrm{h} / \mathrm{mL})^{\mathrm{a}}\end{array}$ & $\begin{array}{c}\text { Effluent } \\
\text { column rate } \\
(\mu \mathrm{mol} / \mathrm{h} / \mathrm{mL})^{\mathrm{a}}\end{array}$ & $\begin{array}{c}\text { Total RPC } \\
\text { reactor rate } \\
(\mu \mathrm{mol} / \mathrm{h} / \mathrm{mL})^{\mathrm{b}}\end{array}$ & $\begin{array}{c}\text { Model } \\
\text { simulated } \\
\text { biomass } \\
(\mathrm{mg})\end{array}$ \\
\hline 77 & 0.071 & 0.067 & 0.042 & 2.7 \\
150 & 0.037 & 0.033 & 0.025 & 1.7 \\
\hline
\end{tabular}

${ }^{\mathrm{a}}$ Value calculated as total moles cDCE formed, divided by total incubation time and reactor volume.

${ }^{\mathrm{b}}$ Value calculated as cDCE concentration in RPC effluent that day, divided by pumping rate and total RPC reactor volume. 
revealed approximately $12 \mathrm{mM}$ propionate and $10 \mathrm{mM}$ acetate were present from lactate fermentation, and that the RPC was not electron donor limited. All effluent protein samples, taken approximately every thirty days, were below the $0.5 \mathrm{mg} / \mathrm{L}$ detection limit, indicating that suspended cells were unlikely contributing significant dechlorination activity, and that the modeling assumption of $15 \%$ cell sloughing is reasonable. Bacterial growth in the waste collection bottle indicated cells were sloughing and exiting the RPC, despite the inability to detect them through protein analysis of the effluent samples.

\section{RPC Modeling}

Because neither competitive inhibition, Haldane inhibition, or threshold inhibition modeling could describe our CFSTR data, we chose to only investigate our toxicity model in analyzing the continuously-fed RPC data. The RPC model was calibrated by establishing the $X_{0}$ that fit TCE dechlorination observed between days 5.7 and 9.6, consistent with the approach used in the CFSTR analysis. The same $k_{\max \text {,TCE }}$ from the batch and CFSTR experiments was used for the RPC simulations. After model calibration, the $K_{\mathrm{t}, \mathrm{cDCE}}$ coefficient was adjusted until the simulated rate of TCE increase between days 97 and 105 matched the experimental observations. Adjustments of $K_{\mathrm{t}, \mathrm{cDCE}}$ alone could not simulate the observed plateau of TCE concentrations observed from days 103 to 127 or the ultimate buildup of TCE and CDCE decreases, beginning on day 128 . Adjusting only the $K_{\mathrm{t}, \mathrm{cDCE}}$ parameter resulted in either a transient spike of TCE that returned to negligible concentrations by day 110 , or predicted premature reactor failure beginning at day 101 (not shown). By including the $K_{\mathrm{t}, \mathrm{TCE}}$ term, the observed plateau and then buildup of TCE, accompanied by flushing of cDCE from the RPC could be simulated (Fig. $4 \mathrm{a}$ ). As with the CFSTR model, the $K_{\mathrm{t}, \mathrm{cDCE}}$ and $K_{\mathrm{t}, \mathrm{TCE}}$ coefficients are sensitive and were adjusted to fit the RPC experimental observations. Sensitivity analyses to these coefficients are supplied in the Supplemental data section, including Figures S2a and S2b. The sensitivity analysis, discussed in the Supplemental data section, showed the simulations were very sensitivity to $\pm 10 \%$ changes in the $K_{\mathrm{t}, \mathrm{CDCE}}$ and $K_{\mathrm{t}, \mathrm{TCE}}$ and illustrate the non-linear nature of the system of equations that are being solved.

The predicted biomass from the toxicity model is shown in Figure 4b. As with the CFSTR model, the RPC modeled biomass decreases at later time are associated with increasing TCE concentrations. Parameters used for the RPC model are summarized in Table II. All but the $K_{\mathrm{t}, \mathrm{cDCE}}$ and $K_{\mathrm{t}, \mathrm{TCE}}$ and $X_{0}$, terms were the same as those in the EV-cDCE batch and CFSTR models. Note the ratio of $K_{\mathrm{t}, \mathrm{cDCE}} / K_{\mathrm{t}, \mathrm{TCE}}$ for the RPC fitted model was 3.7, nearly identical to the ratio of $K_{\mathrm{OW}}$ for TCE/cDCE (3.6), and the $K_{\mathrm{M} / \mathrm{B}}$ ratio for TCE/cDCE (3.5), and is consistent with the CFSTR simulation results. This further supports previous work relating the degree of solvent toxicity to concentrations in the cell wall (Chu, 2004; Chu et al., 2006; Isken et al., 1999; Sikkema et al., 1994).
Table IV. Impacts of modeled $f_{\mathrm{s}}$ on toxicity coefficients for the RPC.

\begin{tabular}{lcc}
\hline$f_{\mathrm{s}}$ (unitless) & $K_{\mathrm{t}, \mathrm{CDCE}}(\mu \mathrm{M})$ & $K_{\mathrm{t}, \mathrm{TCE}}(\mu \mathrm{M})$ \\
\hline 0 & 2,200 & 605 \\
0.15 & 2,600 & 770 \\
0.50 & 5,000 & 1,400 \\
\hline
\end{tabular}

Since the modeled $f_{\mathrm{s}}$ (Eq. 3 ), $K_{\mathrm{t}, \mathrm{cDCE}}$ and $K_{\mathrm{t}, \mathrm{TCE}}$ (Eq. 8 , part I) all directly impact cell loss $(\mathrm{d} X / \mathrm{d} t)$, modifying $f_{\mathrm{s}}$ will impact modeled toxicity, and is therefore an important term to rigorously quantify in more detailed studies. Note, we do not fit $f_{\mathrm{s}}$ to our data, but assumed a typical $f_{\mathrm{s}}$ value (Telgmann et al., 2004) and fit the toxicity terms. Changing $f_{\mathrm{s}}$ from our reported 0.15 to 0 or 0.5 produced different $K_{\mathrm{t}}$ coefficients for equal fits to the data and modeled active biomass (Fig. 4a and b), as summarized in Table IV. With the assumption of no cell sloughing $\left(f_{\mathrm{s}}=0\right)$, the $K_{\mathrm{t}, \mathrm{cDCE}}$ and $K_{t, \text { TCE }}$ coefficients had to be lower (more toxic) to achieve sufficient loss of active cells to fit the data. Even in this scenario, the $K_{\mathrm{t}, \mathrm{cDCE}}$ and $K_{\mathrm{t}, \mathrm{TCE}}$ coefficients are higher (less toxic) than for the CFSTR or batch-fed cells (Table II), indicating the RPC biomass was more resistant to $\mathrm{CAH}$ toxicity than CFSTR biomass. Less inhibition or toxicity in attached growth when compared to chemostats has been observed in previous studies (Anwar et al., 1992; Welin et al., 2003).

Failure of the RPC dechlorination performance happened shortly after increasing influent flows from 6 to $12 \mathrm{~mL}$ /day (on day 101). To test if failure was due to increased advection of cells, we performed simulations excluding the $K_{\mathrm{t}, \mathrm{CDCE}}$ and $K_{\mathrm{t}, \mathrm{TCE}}$ terms while modifying $f_{\mathrm{s}}$ of Equation (3). Simulated RPC failure in the absence of the toxicity terms did not occur until $f_{\mathrm{s}}$ was adjusted above 0.85 , and did not produce the transient TCE plateau measured between days 103 and 131. Increasing the influent flow from 6 to $12 \mathrm{~mL} /$ day represents only a $0.2 \%$ change in the total flow rate (including recirculation). Advective cell loss from the RPC is therefore unlikely a significant factor in lost performance. The proposed model indicates the sudden increase in loading elevated TCE concentrations to enhance toxicity, resulting in the net cell decay rate becoming greater than the net biomass growth rate, which is illustrated by the decline in total active biomass in Figure $4 \mathrm{~b}$. This decline is supported by the results of the mini-column batch tests which show approximately a 50\% reduction in dechlorination rates from day 77 to 150 (Table III), consistent with the simulated reduction in biomass. Future direct experiments are necessary to test this observation, using approaches such as the mini-column method demonstrated here.

Adding Yu and Semprini's (2004) Haldane inhibition terms, or modeling with Haldane inhibition in the absence of our toxicity terms could not produce a model fit to the data (not shown). Modeling the RPC reactor with only Haldane inhibition $\left(K_{\mathrm{I}, \mathrm{H}-\mathrm{TCE}}\right)$ resulted in simulations with either complete dechlorination of TCE to $\mathrm{CDCE}$ and no reactor failure (for $K_{\mathrm{I}, \mathrm{H}-\mathrm{TCE}} \geq 624 \mu \mathrm{M}$ ), or loss of TCE 
dechlorination and biomass $(X)$ by day 30 (for $K_{\mathrm{I}, \mathrm{H}-}$ $\mathrm{TCE} \leq 623 \mu \mathrm{M})$. The toxicity model, with the exclusion of Haldane inhibition however, matches the CAH data very well (Fig. 4a), indicating concentration-based toxicity is a likely reason for lost activity.

Simulations were also run with modified half-velocity, $K_{S}$, values to determine whether changing effective $K_{S}$ for attached growth could predict loss of dechlorination, or impact toxicity coefficients. Increasing reported $K_{\mathrm{S} \text {,TCE }}$ from values in Table II by a factor of 10 did not produce a simulation resulting in loss of TCE dechlorination if excluding the $K_{\mathrm{t}}$ toxicity terms, and had a small impact on the model outcome while including $K_{\mathrm{t}}$ toxicity terms. This analysis indicates a shift in culture's $K_{\mathrm{s}, \mathrm{TCE}}$ is not a sensitive factor in the response to the simulated TCE and cDCE concentrations.

\section{Conclusions}

Unsuccessful attempts to simulate observations using Haldane or other inhibition for the batch-fed, CFSTR or RPC reactor data indicates that the proposed toxicity model better represents long term effects of high CAH concentration exposure. It is possible that a combination of inhibition and toxicity were experienced by the cultures tested, though the assumption of Haldane inhibition combined with the proposed toxicity model did not result in better model fits to the experimental observations.

The proposed toxicity model produced $K_{\mathrm{t}, \mathrm{CDCE}}$ values in the different systems, from low to high: batchfed $<$ CFSTR $<$ RPC (see Table II, and Table I of part I). This suggests batch-fed cells were the most sensitive to toxicity, followed by the CFSTR grown cells, with attached cells in the RPC being the least sensitive. This trend is consistent with other observations of increased resistance often found in chemostat cells compared to batch-fed cells (Chang and Alvarez-Cohen, 1996; Piringer and Bhattacharya, 1999; Qu and Bhattacharya, 1997) and in attached growth cells compared to batch suspended cells (Harrison et al., 2007; Stewart and Costerton, 2001; Walters et al., 2003), or chemostat suspended cells (Anwar et al., 1992; Welin et al., 2003). No attached growth was visually observed in the previous batch experiments (Sabalowsky and Semprini, in press), or in the CFSTR reactor. We therefore believe the different toxicity coefficients reflect differences in the biological and transport processes of suspended versus attached cell systems regarding toxicity or protection from it.

While the long retention times of 16.8 and 25.3 days used through most of our CFSTR operation seem to be of a similar magnitude to the 60-day batch experiments presented in part I (Sabalowsky and Semprini, in press), the CFSTR is distinctly different in the continued slow addition of TCE instantaneously mixed into the reactor versus daily spikes of high $(\sim 800 \mu \mathrm{M})$ TCE concentrations in the batch-fed systems. The reasons for enhanced resistance in chemostat versus batch-fed cells are still not fully known, though cells in exponential growth, such as can occur in batch-fed systems, appear to be more susceptible to toxic chemical exposure than those in a stationary phase, as occurs in continuously fed systems (Piringer and Bhattacharya, 1999). Toxicity as it relates to exponential growth, stationary cells, acclimated chemostat-grown cells tested in batch-toxicity experiments, and resulting community transcriptional responses would be necessary to illuminate such differences observed in our experiments and subsequent toxicity coefficient differences.

Mechanisms that may improve resistance of attached cells compared to planktonic cells can include cell signaling, diverse phenotypes, diffusion limitations, biosorption, and cell differentiation within biofilms (Harrison et al., 2007). Diffusion limitation is only one of the possible reasons for attached cell resistance, even in a fully penetrated biofilm. For example, a Pseudomonas biofilm has exhibited antibiotic resistance despite full antibiotic penetration of the biofilm (Walters et al., 2003). Future experimentation related to attached cell resistance mechanisms described by Harrison et al. (2007) would be required to understand the differences between the RPC and CFSTR responses to high CAH concentrations and related toxicity coefficients modeled here.

The inability of Haldane or threshold inhibition models to describe these CFSTR and RPC data suggests the proposed toxicity/decoupler model best characterizes the observed effects of long-term exposure to high $\mathrm{CAH}$ concentrations. The ratios of fitted $K_{\mathrm{t}, \mathrm{CDCE}}$ and $K_{\mathrm{t}, \mathrm{TCE}}$ fitted values further supports the concept of toxicity being proportional to cell wall partitioning concentrations (Chu, 2004; Chu et al., 2006; Isken et al., 1999). Future work is required to more directly test the toxicity model proposed in this study, both in batch-fed growth, and in alternative growth modes.

Funding for this research was provided by NSF Integrative Graduate Education and Research Traineeship Program (IGERT), U.S. EPA Western Region Hazardous Substance Center (Grant \# R-828772), and National Institute of Environmental Health Sciences (Graduate Training Grant \#1P42 ES10338). This article has not been reviewed by the above agencies and no endorsement should be inferred.

\section{References}

Adamson DT, Lyon DY, Hughes JB. 2004. Flux and product distribution during biological treatment of tetrachloroethene dense non-aqueousphase liquid. Environ Sci Technol 38(7):2021-2028.

Amos BK, Christ JA, Abriola LM, Pennell KD, Löffler FE. 2007. Experimental evaluation and mathematical modeling of microbially enhanced tetrachloroethene (PCE) dissolution. Environ Sci Technol 41(3):963970.

Anwar H, Strap JL, Costerton JW. 1992. Kinetic interaction of biofilm cells of Staphylococcus aureus with cephalexin and tobramycin in a chemostat system. Antimicrob Agents Chemother 36(4):890-893.

Azizian MF, Behrens S, Sabalowsky A, Dolan ME, Spormann AM, Semprini L. 2008. Continuous-flow column study of reductive dehalogenation of PCE upon bioaugmentation with the Evanite enrichment culture. J Contam Hydrol 100(1-2):11-21. 
Carr CS, Garg S, Hughes JB. 2000. Effect of dechlorinating bacteria on the longevity and composition of PCE-containing nonaqueous phase liquids under equilibrium dissolution conditions. Environ Sci Technol 34(6):1088-1094.

Chang HL, Alvarez-Cohen L. 1996. Biodegradation of individual and multiple chlorinated aliphatic hydrocarbons by methane-oxidizing cultures. Appl Environ Microbiol 62(9):3371-3377.

Chu MY. 2004. Factors controlling the efficiency of bio-enhanced PCE NAPL dissolution. Ph.D. thesis. Stanford University, Stanford, CA.

Chu MYJ, Kitanidis PK, McCarty PL. 2006. Inhibition-related limitation to biologically enhanced dissolution of chlorinated solvents. Proceedings of the Fifth International Conference on Remediation of Chlorinated and Recalcitrant Compounds, Monterey, CA. May 2006; ISBN 157477-157-4 Battelle Press, Columbus, OH.

Cope N, Hughes JB. 2001. Biologically-enhanced removal of PCE from NAPL source zones. Environ Sci Technol 35(10):2014-2021.

Cupples AM, Spormann AM, McCarty PL. 2004. Vinyl chloride and cisdichloroethene dechlorination kinetics and microorganism growth under substrate limiting conditions. Environ Sci Technol 38(4): 1102-1107.

Drzyzga O, Gerritse J, Dijk JA, Elissen H, Gottschal JC. 2001. Coexistence of a sulphate-reducing Desulfovibrio species and the dehalorespiring Desulfitobacterium frappieri TCE1 in defined chemostat cultures grown with various combinations of sulphate and tetrachloroethene. Environ Micro 3(2):92-99.

Duhamel M, Wehr SD, Yu L, Rizvi H, Seepersad D, Dworatzek S, Cox EE, Edwards EA. 2002. Comparison of anaerobic dechlorinating enrichment cultures maintained on tetrachloroethene, trichloroethene, cisdichloroethene and vinyl chloride. Water Res 36(17):4193-4202.

Gossett JM. 1987. Measurement of Henry's law constants for C1 and C2 chlorinated hydrocarbons. Environ Sci Technol 21(2):202-208.

Gupta M, Gupta A, Suidan MT, Sayles GD. 1996. Biotransformation rates of chloroform under anaerobic conditions. 2. Sulfate reduction. Water Res 30(6):1387-1394.

Harrison JJ, Ceri H, Turner RJ. 2007. Multimetal resistance and tolerance in microbial biofilms. Nature Rev Microbiol 5(12):928-938.

Isalou M, Sleep BE, Liss SN. 1998. Biodegradation of high concentrations of tetrachloroethene in a continuous flow column system. Environ Sci Technol 32(22):3579-3585.

Isken S, Derks A, Wolffs PFG, de Bont JAM. 1999. Effect of organic solvents on the yield of solvent-tolerant Pseudomonas putida S12. Appl Environ Microbiol 65(6):2631-2635.

Kao CM, Chen SC, Liu JK. 2001. Development of a biobarrier for the remediation of PCE-contaminated aquifer. Chemosphere 43(8):10711078.

Ma X, Novak PJ, Semmens MJ, Clapp LW, Hozalski RM. 2006. Comparison of pulsed and continuous addition of $\mathrm{H}_{2}$ gas via membranes for stimulating PCE biodegradation in soil columns. Water Res 40(6): 1155-1166.

Perry RH, Green DW, Maloney JO. 1997. Perry's chemical engineers handbook. 7th edition. New York: McGraw Hill.

Piringer G, Bhattacharya SK. 1999. Toxicity and fate of pentachlorophenol in anaerobic acidogenic systems. Water Res 33(11):2674-2682.

Qu MB, Bhattacharya SK. 1996. Degradation and toxic effects of acrylic acid on anaerobic systems. J Environ Eng-ASCE 122(8):749-756.
Qu M, Bhattacharya SK. 1997. Toxicity and biodegradation of formaldehyde in anaerobic methanogenic culture. Biotechnol Bioeng 55(9):727736.

Sabalowsky AR. 2008. Electron donor and chlorinated ethene effects on activity and community composition in anaerobic reductively dechlorinating consortia. Ph.D. thesis, Oregon State University, Corvallis.

Sabalowsky AR, Semprini L. (in press). Trichloroethene and cis-1,2dichloroethene concentration-dependent toxicity model simulates anaerobic dechlorination at high concentrations: I. Batch-fed reactors. Biotechnol Bioeng.

Schaefer CE, Condee CW, Vainberg S, Steffan RJ. 2009. Bioaugmentation for chlorinated ethenes using Dehalococcoides sp.: Comparison between batch and column experiments. Chemosphere 75(2):141-148.

Shellenberger K, Logan BE. 2002. Effect of molecular scale roughness of glass beads on colloidal and bacterial deposition. Environ Sci Technol 36:184-189.

Sikkema J, de Bont JAM, Poolman B. 1994. Interactions of cyclic hydrocarbons with biological membranes. J Biol Chem 269(11):80228028.

Singhal N, Jaffe P, Maier W, Jho EH. 2007. The opposing effects of bacterial activity and gas production on anaerobic TCE degradation in soil columns. Chemosphere 69(11):1790-1797.

Sleep BE, Seepersad DJ, Mo K, Heidorn CM, Hrapovic L, Morrill PL, McMaster ML, Hood ED, LeBron C, Lollar BS, Major DW, Edwards EA. 2006. Biological enhancement of tetrachloroethene dissolution and associated microbial community changes. Environ Sci Technol 40(11): 3623-3633.

Stewart PS, Costerton JW. 2001. Antibiotic resistance of bacteria in biofilms. Lancet 358(9276):135-138.

Telgmann U, Horn H, Morgenroth E. 2004. Influence of growth history on sloughing and erosion from biofilms. Water Res 38(17):36713684.

Walters MC III, Roe F, Bugnicourt A, Franklin MJ, Stewart PS. 2003. Contributions of antibiotic penetration, oxygen limitation, and low metabolic activity to tolerance of Pseudomonas aeruginosa biofilms to ciprofloxacin and tobramycin. Antimicrob Agents Chemother 47(1): 317-323.

Welin J, Wilkins JC, Beighton D, Wrzesinski K, Fey SJ, Mose-Larsen P, Hamilton IR, Svensäter G. 2003. Effect of acid shock on protein expression by biofilm cells of Streptococcus mutans. FEMS Microbiol Lett 227(2):287-293.

Yang Y, McCarty PL. 1998. Competition for hydrogen within a chlorinated solvent dehalogenating anaerobic mixed culture. Environ Sci Technol 32(22):3591-3597.

Yang Y, McCarty PL. 2000. Biologically enhanced dissolution of tetrachloroethene DNAPL. Environ Sci Technol 34(14):2979-2984.

Yang Y, McCarty PL. 2002. Comparison between donor substrates for biologically enhanced tetrachloroethene DNAPL dissolution. Environ Sci Technol 36(15):3400-3404.

Yu S, Semprini L. 2004. Kinetics and modeling of reductive dechlorination at high PCE and TCE concentrations. Biotechnol Bioeng 88(4):451464.

Zheng D, Carr CS, Hughes JB. 2001. Influence of hydraulic retention time on extent of PCE dechlorination and preliminary characterization of the enrichment culture. Biorem J 5(2):159-168. 